\title{
O DISCURSO DE GETÚlIO VARGAS E A PRODUÇÃO DE SENTIDOS SOBRE AS MASSAS SOCIAIS
}

\section{GETÚLIO VARGAS SPEECH AND SENSE PRODUCTION ON SOCIAL MASSES}

\author{
Alan Miranda Silva ${ }^{1}$ \\ ${ }^{1}$ Mestrado em Ciências da Linguagem, Universidade do Vale do Sapucaí, Pouso Alegre, MG, alanmirandas@yahoo.com.br
}

\section{Resumo}

O discurso de Getúlio Vargas no tempo em que foi presidente da República Federativa do Brasil vivenciado em dois momentos, sendo no seu primeiro mandato (entre os anos de 1930 a 1945), e no segundo mandato (1951 a 1954), se tornando assim, o presidente que mais tempo governou o Brasil, demonstra a produção de sentidos do sujeito na posição de poder. Esses dois momentos de posse constituem elementos para analisar as condições vivenciadas na história, e averiguar como a produção de uma discursividade se hegemoniza certos sentidos a seus interlocutores, produzindo efeitos de sentido que sustentam, explicam, e legitimam a ruptura dos efeitos de sentidos que produziram um regime democrático antes estabelecido no primeiro mandato, o que pode ser averiguado pelo método de $A D$. $O$ método de Análise do Discurso (AD) concebe o interdiscurso como algo que constitui todos os discursos dando-lhes materialidade ideológica, histórica, e inconsciente, porque aí se inscreve os discursos outros que materializam os modos de relação social; nesse sentido, considera a linguagem como constitutiva dos sujeitos que se inscrevem/filiam as estratégias de interlocução, a partir de posições sociais ou de determinadas conjunturas históricas. $\mathrm{O}$ sujeito, na posição de poder, pensa poder lançar mão de discursos para expor, informar, convencer etc. aqueles que, em seu imaginário, compõem a 'massa social', acreditando que ambos, ele e os outros, são norteados pelos mesmos anseios e valores de uma mesma cultura e de uma mesma história, constituídos e interpelados ideologicamente produzindo os mesmos efeitos de sentidos. Assim, este artigo visa um estudo da possibilidade de controle da direção de sentidos sobre as "massas" sociais, nos discursos do sujeito presidente Getúlio Vargas, o que outrora pode ser analisado nos seus discursos de posse. Na sustentação na teoria da argumentação/retórica argumentativa, buscou-se a possibilidade de tentar responder a questão "o que (não) há no discurso do político que move as massas?", ou criar uma possibilidade de entendimento no decorrer das considerações nos temas e numa análise do discurso de posse, como resultado, pode-se compreender que não podemos falar pelo outro, e também não há garantia de influência ou de convencimento, pois todos são atravessados pela ideologia e suas condições de produção são individuais.

Palavras-chave: Getúlio Vargas. Discurso. produção de sentidos. posição de poder. massas sociais.

\begin{abstract}
The speech of Getúlio Vargas when he was president of the Federative Republic of Brazil experienced in two moments, being in his first term (from 1930 to 1945), and in the second term (1951 to 1954), thus becoming, the president who has ruled Brazil the longest, demonstrates the subject's production of meanings in the position of power. These two moments of possession constitute elements to analyze the conditions experienced in history, and to ascertain how the production of a discursivity hegemonizes certain meanings to its interlocutors, producing meaning effects that sustain, explain, and legitimize the rupture of the effects of meanings that produced a democratic regime previously established in the first term, which can be ascertained by the AD method. The method of Discourse Analysis (AD) conceives interdiscourse as constituting all discourses giving them ideological, historical, and unconscious materiality, because there inscribes other discourses that materialize the modes of social relationship; In this sense, it considers language as constitutive of the subjects who subscribe / affiliate the strategies of dialogue, based on social positions or certain historical conjunctures. The subject, in the position of power, thinks he can use speeches to expose, inform, convince, etc. those who, in his imagination, compose the 'social mass', believing that both he and the others are guided by the same longings and values of the same culture and the same history, constituted and challenged
\end{abstract}


ideologically producing the same sense effects. . Thus, this article aims at a study of the possibility of controlling the direction of meaning over the social "masses", in the speeches of the subject president Getúlio Vargas, which can once be analyzed in his possession speeches. In support of the theory of argumentation / argumentative rhetoric, we sought the possibility of trying to answer the question "what (not) is in the discourse of the politician who moves the masses?", Or create a possibility of understanding in the course of considerations on the themes. and in an analysis of the possession discourse, as a result, it can be understood that we cannot speak for the other, and there is no guarantee of influence or persuasion either, because all are crossed by ideology and their conditions of production are individual.

Keywords: Getúlio Vargas. Speech. Sense production. Position of power. Social masses.

How to cite this article:

SILVA, Alan Miranda. O discurso de Getúlio Vargas e produção de sentidos sobre as massas sociais. Interação, Varginha, MG, v. 21, p.90 - 107, 2019. ISSN 1517-848X / ISSN 2446-9874.

Disponível em: http://periodicos.unis.edu.br/index.php/interacao/article/view/247

DOI: https://doi.org/10.33836/interacao.v21i2.281

\section{INTRODUÇÃO}

Getúlio Vargas foi um presidente marcado por acontecimentos com diversidades polêmicas em seus discursos ao longo da sua história como Chefe do Estado em seus dois mandatos.

Para compreender esse processo de produção de sentidos e sua relação de forças, fazendo com que determinados acontecimentos ganhem registros nos livros de história e outros não, observamos alguns momentos políticos do sujeito Vargas. São momentos outrora discutidos, analisados por pesquisadores, jornalistas, teóricos, dada sua importância e complexidade para a compreensão de nossa historicidade enquanto nação.

Contudo, compreendemos que há aí algo que marca em relação a essa disputa por significar esses momentos, porque há algo comum, que se repete e que desliza, a posição sujeito presidente da república, que podemos descrever, a princípio, como sendo ocupada pelo mesmo indivíduo bio-psico-social - Getúlio Vargas - a mesma pessoa física juridicamente falando, na mesma posição de poder, mas produzindo posições sujeito diferentes; produzindo, portanto, dizeres diferentes, sentidos outros pelos quais também se constitui.

Inquietados pela questão sobre a existência de algo no discurso do político com a possibilidade de mover as massas há outrora a possibilidade de analisar o discurso do político legitimado de alguma forma como garantia de controle da direção de sentidos, pois há o que considerar duas textualidades representativas para pensar essa questão, os dois discursos de posse do sujeito presidente da república Getúlio Vargas em dois momentos distintos da história brasileira, o período considerado entre 1930-1945, com suas subdivisões, e o período de 19511954.

Observamos ainda que o discurso tem sua ordem própria, e, pensado como tal, distinguese da língua, mas a supõe como base material. Os sentidos se produzem enquanto efeitos nessa ordem. $E$, nela também, os sujeitos se significam e fazem significar. $O$ discurso tem a língua como 
condição de possibilidade, lugar de sua materialidade. De outra forma dito, a língua constitui a superfície material em que se efetivam os processos discursivos, nos quais se produzem os efeitos de sentido.

Outrossim, este artigo trata de uma visão do sujeito Vargas e a produção de sentidos sobre as massas mediante o conteúdo/intenção proposto em seu discurso.

\section{METODOLOGIA}

O método utilizado neste artigo é a Análise de Discurso, na qual não se buscam regras categóricas na materialidade dos enunciados, nem a verdade absoluta, porque visa a pensar os sentidos dimensionando-os no tempo-espaço das práticas linguageiras do sujeito. Nem tampouco se pode achar que essa teoria usa um método científico que consiste em observar fatos que permitem ao observador descobrir leis gerais que presidem estes fatos, levando em consideração três procedimentos: a observação, a hipótese e a experimentação. Porque só isso não dá conta de abranger os efeitos de sentido. É preciso lançar mão da complexa relação de constituição entre sujeito, língua e história. O observador descompromissado, o cientista neutro, não existem.

Lembrando com Orlandi (2012) que teoria, método e objeto e procedimentos de análise estão em relação de consistência, é preciso dizer que o método em Análise de Discurso não é tomado positivistamente, como aplicação automática da teoria, tendo em vista que há uma mediação entre teoria e análise que se materializa na busca dos procedimentos próprios ao objeto que constitui questão para o analista, no nosso caso, os discursos escritos e falados da posição de presidente da república por ocasião de sua posse.

Tal procedimento metodológico, como assevera Pêcheux [1982] 2006, p. 54), "não se constitui em duas fases sucessivas, mas de uma alternância, de um batimento, não implicando que a descrição e a interpretação sejam condenadas a se "entremisturar" no indiscernível".

Nosso trabalho metodológico aponta para analisar o objeto levando em conta descrição, interpretação e compreensão, ou seja, apresentar uma descrição da materialidade linguística dos textos selecionados e no mesmo processo dar visibilidade a/buscar compreender como as marcas observadas na materialidade linguageira trabalham produzindo efeitos de sentidos para caracterizar os acontecimentos políticos no discurso de posse de dois momentos do mesmo presidente e como esses acontecimentos discursivos são sobredeterminados pelas condições de produção.

Para atingir os objetivos desse artigo, vamos tomar o método da análise do discurso que procura expor o olhar leitor à opacidade do texto, procura levar em conta que algo fala antes, alhures e independentemente do sujeito que enuncia (interdiscurso), interrogando o funcionamento do discurso, das discursividades que constituem sujeito e sentido fazendo repetir/romper com pré-construídos. Em nosso caso, buscaremos compreender como a noção de massa, e outras a ela conjugadas pelo senso comum como a de influência e a de mudança de comportamento, se relacionam e reforçam o imaginário de um dizer que garantiria pela fala de um sujeito político na posição de presidente da república a aquiescência dos sujeitos interlocutores/ouvintes a suas ideias. Em outras palavras, vamos colocar em suspensão a questão de que um 'sujeito político consegue influenciar opiniões a ponto de causar mudanças de comportamento das massas sociais'.

Tomamos para análise, o modo como a historicidade desse tema constitui a produção de significados e silenciando outros, fazendo-os circular, possibilitando a atualização dos mesmos, a partir daí, por uma memória oficial. Perguntamos, observando o corpus, se não há derivas e resistências que poderiam atualizar outros sentidos não considerados como o oficial. 
Consideramos nessa observação discursiva que a historicidade do texto não está no contexto fora da linguagem, mas na forma como a exterioridade está simbolizada e constituída no próprio texto, no modo de funcionamento de marcas da linguagem que falam essa história.

O objeto teórico construído para essa pesquisa se mostra a partir de recortes direcionados pelos objetivos propostos, ganhando corpo a partir da questão do analista. Nosso corpus discursivo, que já é resultado de um primeiro gesto de análise, é constituído também pela noção de 'massa' e pelas relações que tal noção mantém com noções 'influência', 'comportamento', por exemplo. Ao dar visibilidade a essas relações e seu funcionamento no discurso político, pretendemos compreender como se materializa a aparente/imaginária objetividade de que é possível "influenciar as massas".

Estamos advertidos de que a Análise de Discurso é um dispositivo de leitura e de interpretação, o fazer recorte do objeto leva à determinação da teoria, de seus métodos e procedimentos. Assim, o recorte sobre o material empírico já é um gesto de análise.

\section{O SUJEITO GETÚLIO VARGAS E SUAS POSIÇÕES DISCURSIVAS NA HISTÓRIA}

O homem em estudo é Getúlio Dornelles Vargas nascido na cidade de São Borja, no Estado do Rio Grande do Sul, em 19 de abril de 1882, e faleceu em 24 de agosto de 1954, na cidade do Rio de Janeiro (RJ).

Vargas foi presidente da República Federativa do Brasil entre os anos de 1930 a 1945 em seu primeiro mandato, e de 1951 a 1954 no segundo mandato, se tornando assim, o presidente que mais tempo governou o Brasil. Os quinze anos de governo de Vargas se definiram, ou mesmo estruturaram, pelo nacionalismo e pelo populismo.

Logo após comandar a Revolução de 1930, que derrubou o governo de Washington Luís, ele assumiu o poder neste mesmo ano. Sob seu governo foi promulgada a Constituição de 1934.

Em fatos históricos, Getúlio Vargas no seu período de posição sujeito Chefe de Estado, parece ter levado toda uma massa a sentir-se como seguidora das suas palavras. o longo da história, Vargas se posicionou como um homem indecifrável, seu governo, seus atos o deixaram à beira da interpretação das massas, como herói e/ou ditador.

Em 1937, fechou o Congresso Nacional e instalou o Estado Novo, passando a governar com poderes ditatoriais (centralizador e controlador), criando o Departamento de Imprensa e Propaganda (DIP) para fiscalizar e censurar manifestações contrárias a seu governo.

Dos seus feitos, Vargas criou em 1939 a Justiça do Trabalho, e neste conceito prótrabalhador instituiu o salário mínimo e a Consolidação das Leis do Trabalho (CLT), além dos direitos trabalhistas como carteira profissional, semana de trabalho de 48 horas e férias remuneradas.

A área de infraestrutura do país foi bastante beneficiada pelo seu governo, criando no ano de 1940 a Companhia Siderúrgica Nacional, em seguida, no ano de 1942, a Vale do Rio Doce, e em 1945 a Hidrelétrica do Vale do São Francisco. No ano de 1938, Vargas criou o Instituto Brasileiro de Geografia e Estatística (IBGE).

Saiu do governo em 1945, após um golpe militar.

Em 1950, e seu segundo mandato, Getúlio Vargas voltou ao poder mediante eleições democráticas, onde neste governo deu continuidade à sua política nacionalista, criando instituições pró-Brasil como a Petrobrás. 
Em agosto de 1954, Vargas suicidou-se no Palácio do Catete com um tiro no peito. Deixou uma carta testamento com uma frase que entrou para a história: "Deixo a vida para entrar na história". Até hoje, o suicídio de Vargas gera polêmicas. O que sabemos é que seus últimos dias de governo foram marcados por forte pressão política por parte da imprensa e dos militares. Além disso, a situação econômica do país não era boa, fato que gerava muito descontentamento entre a população.

As diversas posições de Getúlio Vargas levam à construção da sua figura política, enquanto o político manifesta seus anseios por um poder de se pensar em controlar outros sujeitos a partir da realização de um possível imaginário.

\subsection{O discurso do político e o movimento das massas}

A Análise de Discurso analisa as diversas construções ideológicas que se podem encontrar em textos, e também em outros meios que possam produzir sentidos no contexto histórico-social e as condições de produção pelo sujeito.

O sujeito Getúlio Vargas parece produzir efeitos de sentidos em seu discurso que por sua vez, em seus escritos de imposição, provocaram a aceitação social, possibilitando haver um assujeitamento das massas que ouviam seus dizeres, levando assim a produção de sentidos outros a seu favor, ou mesmo contra suas ideias, o que neste movimento pode-se pensar na política do performativo.

Para Pêcheux (2011, p.89) "a política do performativo parece ter representado um papel decisivo: quando dizer equivale a fazer, a política tende a se tornar uma atividade imaginária que se parece ao sonho acordado".

Assim ao buscar entender o sujeito e contexto histórico fica uma pergunta: o que (não) há no discurso do político que move as massas? sociedade:

Orlandi (2003, p. 48) no tema o sujeito e suas formas histórias cita a forma-sujeito em

A forma-sujeito histórica que corresponde à da sociedade atual representa bem a contradição: é um sujeito ao mesmo tempo livre e submisso. Ele é capaz de uma liberdade sem limites e uma submissão sem falhas: pode tudo dizer, contanto que submeta a língua para sabê-la. Essa é a base do que chamamos assujeitamento .

Assim, quando se trata da política das 'massas', sustenta Pêcheux (2014) o par semântico pessoa/coisa e a forma como essa oposição reflete as divisões do pensamento moderno na esfera jurídica pela oposição entre contrato e propriedade, na esfera filosófica pela oposição entre sujeito e objeto, e na esfera moral pela oposição intencional e não intencional.

Ainda de acordo com I Pêcheux (2014, p. 252) e seu texto sobre "as massas populares são um objeto inanimado?", o falar das massas é entendido da seguinte forma:

Falar das massas populares, de mudança política e de revolução, enfim, da história, em termos de pessoas e de coisas, de sujeitos e objetos, de intenções e do estado das coisas, como algo natural, como distinções 
transparentes que aparecem na linguagem sem qualquer ambiguidade, é desconsiderar totalmente a constituição essencial ideológica do discurso e do sentido. (...), contudo, a política tem, indiscutivelmente, efeitos na linguagem, e não são efeitos desconexos.

Percebe-se também neste sujeito político ora em estudo é o efeito de seus dizeres sobre a massa popular e a constituição ideológica de seu discurso na produção de sentidos para aqueles que o ouvem e numa contradição de pensamentos que se permitem ser influenciados, ou mesmo identificados pelo discurso proferido.

\subsection{Os discursos e sua produção de sentidos}

Os discursos de posse da década de 30, assim como o discurso de posse da década de 50 demonstram contradições de um mesmo indivíduo que fora odiado e amado por suas ações, de um sujeito que pela enunciação provoca uma variedade de sentidos e que por isso fez com que as emoções de grande parte dos sujeitos que compõem as massas oscilassem à medida que suas palavras ofuscavam o dito e ampliavam o imaginário.

Ao pensar nas palavras recortadas e o momento histórico que o Brasil estava passando na década de 30 (Lamounier, 1992), se pode ler a insistência de um sujeito-ditador que visa o controle das massas (se é que seja possível), mediante o discurso que determina a atitude coletiva.

Para Cotrim (1999, P. 68) na década de 30, no Brasil, diferentemente, o latifúndio procede "de outra gênese histórica, posto, desde suas formas originárias, no universo da economia mercantil pela empresa colonial". Trazido à cena do mundo moderno na condição subordinada de colônia de exploração, subordinação caracterizada pela organização de suas relações de produtos internos, e, portanto, também de suas classes sociais, de acordo com interesses e necessidades das capitais metropolitanas, o Brasil inicia de fato seu processo de industrialização.

Vargas em seus discursos de posse produziu efeito de sentidos em que a língua e o discurso se constituem em uma oposição diferente da linguagem e da forma de dizer, por isso a valia da análise dos discursos de posse corresponde ao movimento natural do pensamento, dos valores atribuídos pelo discurso ao significado em língua, demonstrando por um momento seu carisma com aquilo que é do povo e para o povo, no entanto, em um momento anterior a imposição de poder que muitas vezes foi levado o respeito pelo temor na produção de sentidos.

\section{PROPAGANDA E PRODUÇÃO DE SENTIDOS}

Pode-se pensar que sujeito, história e linguagem, se constituem para a formação do cenário atual/vivenciado, as produções de sentidos interpelam o interlocutor, enquanto é atravessado pela ideologia. Para Orlandi (2009, p. 26) "a análise de discurso visa a compreensão de como um objeto simbólico produz sentidos, como ele está investido de significância para e por sujeitos" . Nessa perspectiva, mostra que cada análise em Análise de Discurso é singular, por mobilizar diferentes conceitos/categorias analíticas, o que tem profundos efeitos no resultado final do trabalho do pesquisador, já que cada um lança mão das noções do dispositivo teórico para construir seu dispositivo analítico.

Entretanto, um equívoco interpela o sujeito na posição de poder, pois embora Getúlio Vargas tenha sido um ditador e tenha governado com medidas controladoras e populistas, este 
sujeito foi um presidente cujo governo teve como uma de suas principais marcas o desenvolvimento do país. Para isso tomou medidas favoráveis aos trabalhadores, e sua política econômica gerou muitos empregos no Brasil e suas medidas favoreceram, principalmente, os trabalhadores brasileiros, o que nos faz pensar neste caso sobre o discurso do político e o controle das massas em sua historicidade.

Sobre a propaganda política, o sujeito, relações de poder e produção de sentidos, Pêcheux (2011, p. 76) trata da formação ideológica das massas em questão, como "é o lugar comum de dizer que as propagandas governamentais se intensificam, na esfera capitalista, e também na do 'socialismo existente'."

Ainda segundo o mesmo autor, a questão da propaganda é, pelo menos desde Napoleão, um negócio estratégico, um elemento indispensável no prosseguimento das operações militares contra o inimigo exterior, ou seja, uma longa tradição do Estado, adaptando-se às novas condições da luta contra o proletariado.

Pêcheux (2014, P. 77-80), "historicamente ao perceber que neste mesmo período de tempo está havendo mudanças, coloca que a bio-psicologica da propaganda que se progressivamente formulou, continua a frequentar as preocupações políticas de nosso tempo (...). Seria então necessário fazer história e não psicologia, e interrogar as práticas contraditórias que se instituíram no coração do desenvolvimento capitalista mais do que passar em revista, técnicas psicológicas da propaganda. "

\section{AS MASSAS EXISTEM? O PENSAMENTO DO POLÍTICO SOBRE A POSSIBILIDADE DE MODIFICAR MASSAS}

O que se é analisado no discurso imerso em um cenário engrandecido pela luta de classe, onde o real está movendo a todo momento, e o político significando a produção de sentidos, é o apontamento da subjetividade que se desloca do eu e passa a ser vista como inerente a toda linguagem, o qual na ausência do eu, quando o eu não é enunciado, esta se constitui no funcionamento do discurso. Também, ao político fica o pensamento a possibilidade de mudar a posição das massas, se é que elas existem.

No texto de Pechêux (2011, P. 252) , o autor escreve que "o par semântico pessoa/coisa, que 'cola' sem problema aparente nos enunciados da vida cotidiana, tem-se a aplicação quando se trata da política das massas; contudo, a política tem, indiscutivelmente, efeitos na linguagem, e não são efeitos desconexos." O que se pode pensar é na intenção da proposta de mudança de comportamento das massas, mas para isso o discurso já foi inserido na produção de sentido dos sujeitos-público.

Pechêux (2011, P. 266) ao tratar dos sujeitos políticos das reformas radicais, denota a ilusão tocada pelas questões do poder de Estado, como segue:

A análise permite observar a relação entre concepções de poder do Estado e posição de classe, em particular a posição de classe da intelectualidade pequeno burguesa. Nosso exame da oposição entre direita e esquerda ressalta a oscilação entre uma concepção explicitamente reformista de transformações radicais no interior da atual estrutura política, e uma concepção que desde o princípio se coloca acima de qualquer consideração relativa ao poder de Estado. 
O governo provisório de Vargas nesta época como historicamente sabido, foi cercado de altos e baixos no sentido sócio-político, o que influenciara na economia do país, alguns principais atos foram a suspensão da constituição federativa do Brasil, a dissolução do Congresso Nacional (local este que até então representava a democracia), além da dissolução das Assembleias Legislativas e as Câmaras Municipais. Além disso, também destituiu prefeitos e governantes dos estados, eliminou as prerrogativas individuais e instituiu um tribunal de exceção para julgar crimes políticos, estes dados e fatos são encontrados na obra de Neto (2013, p.08) o qual o autor ainda complementa com o contraste dos "outubristas" que argumentavam sobre uma possível ordem legal em prol da "República Nova": "Essa obra prévia de desentulho, a ditadura só poderá dar por concluída quando houver separado, criteriosamente, o joio do trigo, os elementos imprestáveis, inadequados ou apodrecidos dos esteios bons que também se encontram sob os destroços da velha ordem."

Ao se tratar destas questões de classe, logo nos vem a aparecer no pronunciamento de 1930, ao ser descrito "a revolução escapou, por isso mesmo, ao exclusivismo de determinadas classes", isso nos vem trazer sentido no gesto de leitura do fato, ou seja, na injunção, presente em toda a manifestação da linguagem que gera a interpretação; sendo assim como podemos interpretar 'escapou' e 'exclusivismo'?

Está muito claro para o analista que as formações discursivas que são de ordem ideológica se dão pelas condições históricas, todavia, toda prática discursiva está inscrita no complexo contraditório, desigual e sob determinado das formações ideológicas para a interpretação dos discursos.

Pode-se dizer que aquilo que é escrito é impresso na contextualização inserida pelo leitor, sendo este um ponto crucial da análise deste documento que aqui está havendo uma tentativa de interpretação, pois o momento que este documento foi escrito para que depois fosse pronunciado por um sujeito que ocupa a posição de Chefe de Estado, mediante uma revolução política, tem sua grande expressividade, ganha força pela ideologia em que todos os outros sujeitos estão imersos, pois não é possível fugir disso, mesmo porque a tentativa já é uma produção desta ideologia em movimento.

O gesto da escrita, neste caso no documento de posse é um objeto de suma importância que expressa o que muitos já estão pensando ou não, mas que independente disso, traz a memória discursiva que desloca da memória como virtualidade de significações.

Para tratar de significações de escritas, citamos o que Pfeiffer (2000, p. 251-283) escreve sobre a imprevisibilidade do modo de recepção dos leitores, conforme segue abaixo:

A imprevisibilidade do modo de recepção dos leitores era controlada pelo mercado interno através da fragmentação das edições em fascículos, das extrações seriadas de impressos, e das edições de livros feitas por subscrição antecipada. Além disso, procurou-se didatizar o máximo possível as obras, fazendo delas obras mais próximas de manuais do que de obras técnico-científicas. Por outro lado, foram produzidas muitas obras voltadas ao lazer, ao círculo familiar e privado, ao serão e à leitura em voz alta. Isso foi feito de modo a aproximar o leitor ao mercado de consumo das obras impressas. Percebemos, então, que o imaginário sobre o público-leitor começa a mudar. Há todo um trabalho de popularização deste público, com o que é acirrada a dicotomia entre um público de elite capaz de interpretação e um público incapaz de interpretar, precisando de obras 
facilitadas e, portanto, superficiais e irrelevantes. A interpretação, entendida como exterior à linguagem, é para poucos.

Ao citar Pfeiffer no trecho acima, pensamos em analisar os efeitos do pronunciamento nos sentidos das massas, pois a autora traz pontos que se ligam à possibilidade proposital do pronunciamento, pois quando ela diz "A imprevisibilidade do modo de recepção dos leitores era controlada pelo mercado interno através da fragmentação das edições em fascículos" analisamos os trechos produzidos neste discurso de posse, neste contexto, ou seja, nos elementos externos ao texto que servem para ampliar a sua significação global, foram construídos dentro da constituição histórica da dimensão física e racional buscando prever a imprevisibilidade da recepção do leitor que outrora pode-se tornar ouvinte, mas neste caso, ficaremos somente com a análise da escrita do discurso de posse, e mesmo em ambos, é realizado um estudo do cenário, da história e dos elementos para produzir sentidos e como consequência a possibilidade de incitar o comportamento e/ou pensamento daquele que lê e que torna em sua coletividade "as massas" que são direcionadas ao assujeitamento, já que o indivíduo vive na ideologia (de acordo com Althusser).

Pensamos também no impacto de construtividade e convicção a ser evidenciada quando o discurso foi pronunciado no dia da posse, pois até mesmo uma escrita trabalhada em temáticas diferenciadas, com teor cultural ou técnico/científico, produz efeitos no sujeito nas condições que ele recebe, de acordo com Pfeiffer "produzidas muitas obras voltadas ao lazer, ao círculo familiar e privado, ao serão e à leitura em voz alta", ou seja, aqui também estamos tratando da memória do efeito do pronunciamento lido, fazendo o enunciado, com os elementos ditos com sua função enunciativa que muda de acordo com as condições de produção.

O último ponto do trecho de Pfeiffer que queremos chamar a análise para a intepretação do discurso escrito de Vargas direcionado às massas no contexto de sua posse, é onde ela diz: "há todo um trabalho de popularização deste público, com o que é acirrada a dicotomia entre um público de elite capaz de interpretação e um público incapaz de interpretar, precisando de obras facilitadas e, portanto, superficiais e irrelevantes", onde analisamos o recorte "há todo um trabalho de popularização deste público", o trabalho para levar a mensagem correta, direcionada para constituir sentidos que geram a possibilidade de uma interpretação, para o favoritismo do governo em questão, visando trazer as massas a seu fazer, na posição assujeitada e favorável ao pensamento do sujeito enunciador.

Outro recorte do trecho de Pfeiffer é "a dicotomia entre um público de elite capaz de interpretação e um público incapaz de interpretar, precisando de obras facilitadas e, portanto, superficiais e irrelevantes", ao pensarmos numa metáfora para esta representação tem-se a possibilidade "influenciar o público dentro de suas condições", todavia, o imaginário, pode-se fazer entender, ou buscar a interpretar que há uma possibilidade de controlar aquilo que é chamado de 'influenciar', pois não se faz concebível que alguém influencie outro, já que todos os sujeitos estão inseridos na ideologia já constituída.

Portanto, a ideia de trabalhar a dicotomia, ou seja, essa subjetividade para alcançar os sujeitos que são divididos em capazes e incapazes, leva a proposta de textos, como superfície linguística fechada em si mesma, no lugar do jogo dos sentidos, para trabalhar a linguagem e o funcionamento da discursividade na possibilidade de abranger de alcançar as massas como um todo.

Para conversar com as citações da autora acima citada, colocamos Pêcheux $(1975$,$) ao$ escrever que os indivíduos são interpelados em sujeitos falantes (em sujeitos de seu discurso) por 
formações discursivas que representam 'na linguagem' as formações ideológicas que lhes são correspondentes. Nisto, de acordo com este autor, a interpelação do indivíduo em sujeito de seu discurso se realiza pela identificação (do sujeito) com a formação discursiva que o domina. Então a paráfrase "a revolução escapou" é respondida pela interdiscursividade, na repetição, nos deslocamentos promovidos pelo sujeito-pronunciador que completa em seu discurso outra paráfrase de muita produção de sentidos "fato consumado" quando se trata de que nem os elementos civis venceram a classe armada, ou seja, por sua conduta e por suas palavras as formações discursivas foram interpeladas pelo sujeito-responsável pelo Estado.

Após as citações que colocam sentidos a respeito de massas e sujeito, trazemos o pensamento do fato consumado, em que Vargas no seu pronunciamento faz a tentativa à indução pela interpelação ao recitar "todas as categorias sociais, de alto a baixo, sem diferença de idade e de sexo, comungaram em um idêntico pensamento fraterno e dominador: - a construção de uma Pátria nova, igualmente acolhedora para grandes e pequenos, aberta à colaboração de todos os seus filhos". O recorte que fazemos neste trecho é "a construção de uma Pátria nova", pois aqui Vargas trata de uma Pátria (no singular) para uma pluralidade, que segundo ele, igualmente acolheria toda a coletividade.

Para pensarmos sobre a possibilidade dos efeitos do discurso nas massas para mudar o pensamento coletivo, ou não, Pêcheux (1975), explica que um elemento capital, que diz respeito aos "efeitos paradoxais" são induzidos por duas práticas na forma-sujeito, enquanto relação de desdobramento entre "sujeito da enunciação e sujeito universal", podendo assumir diferentes modalidades que são evidentes, como mostrado a seguir (cf. P.199):

Conhecida na Análise de Discurso como "o bom sujeito" e a identificação, a primeira modalidade consiste numa superposição (um recobrimento) entre o sujeito da enunciação e o sujeito universal, de modo que a tomada de posição do sujeito realiza seu assujeitamento sobre a forma do 'livremente consentido', o que reflete espontaneamente o Sujeito que sofre cegamente a determinação quando realiza efeitos em plena liberdade, assim, seu interdiscurso determina a formação discursiva com a qual o sujeito, em seu discurso, se identifica.

Na outra modalidade, que denota a contra-identificação, conhecida como o "mau sujeito", caracteriza o sujeito no qual o sujeito da enunciação se volta contra o sujeito universal por meio de uma 'tomada de posição' que consiste, em uma separação, e mostra a luta contra a evidência ideológica, sobre o térreo dessa evidência, afetada pela negação, revertida a seu próprio terreno, gerando distanciamento, dúvida, questionamento, contestação e revolta, apresentando uma reversão de traços linguísticos.

Contudo, o pronunciamento de Vargas ao se tratar da "construção de uma nova Pátria", vai além das duas modalidades da forma-sujeito apresentada acima, pois de um lado ele abrange as massas com dizeres como "exclusivismo de determinadas classes" o que nos faz pensar no direcionamento da contra-identificação, tendo aqui o sujeito da enunciação voltado contra o sujeito universal, lançando uma formação discursiva imposta no interdiscurso, do subjetivismo e da política do discurso-contra.

O que se sabe é que a ideologia constitui o discurso, ou seja, se materializa no discurso, sendo o efeito da relação entre o sujeito e a linguagem no cenário onde se encontra, onde os sentidos são produzidos, e o que se identifica com o domínio da formação discursiva que já está no sujeito, por que o imaginário reluta em aceitar que não domina o discurso, para quem diz ou mesmo pronuncia, o que é nosso caso de estudo, a crença do sujeito que possui o domínio de seu discurso, e a ilusão da existência do sentido que quer produzir, esbarra no real, que, muitas vezes, na relutância, vem o pensamento de que este sujeito pode controlar as massas sociais. 


\section{DA REVOLUÇÃO DAS MASSAS À SOMBRA DA RETÓRICA DE GETÚLIO VARGAS}

Segundo Massmann (2017, p. 122) "a nova retórica vem mostrar o modo como o auditório (público) visado modela o discurso, isto é, 'fala-se sempre para e em função de alguém'”. Neste caso a função de implantar aspectos de um novo governo onde os interesses daquele que pronuncia demonstra uma evidência extrema e partidária, com função argumentativa de propósitos impostos às pessoas de um meio.

Não há dúvida de que toda a argumentação é construída e moldada em função do auditório ao qual ela se dirige. A importância dada às opiniões do outro é fundamental à eficácia da argumentação. A consequência disso é, justamente, a centralidade da doxa ou opinião comum. (MASSMANN, 2017, p. 123).

A produção de sentidos da paráfrase "da vontade do povo brasileiro" é a forma como o próprio povo expressa sua vontade, este povo que nesta época enfrenta um contraste político e econômico na história, onde por um lado preza o desenvolvimento necessário dos recursos da nação e de outro lado o sistema econômico decorrente do conflito entre socialismo e capitalismo.

Pode-se analisar o pronunciamento na historicidade do cenário em que este foi produzido, e como se dá a história decorrente do processo social global, que para Bresser-Pereira (2003) é um processo de transformação que mexe com as estruturas econômicas, políticas e sociais de um país gerando transformações significativas que alteram o padrão de vida. Assim vejamos nas palavras do autor:

Em meados do século XIX até 1930, ocorreu no Brasil um desenvolvimento, que iniciou quando a sociedade tradicional entra em crise, quando os critérios racionais começam a superar os tradicionais, quando o capital passa a ter mais importância do que a terra, quando a competência começa a sobrepor-se ao sangue, quando a lei se impõe aos costumes, quando as relações impessoais e burocráticas começam a substituir as de caráter pessoal e patrimonial, quando a sociedade bivalente de senhores e servos, de aristocratas e plebeus, começa a dar lugar a uma sociedade plural, quando o poder político deixa de ser o privilégio de uma oligarquia claramente definida e começa a se tornar cada vez mais difuso, quando a economia de base agrícola tradicional começa a dar lugar a uma economia industrial e moderna, quando a unidade de produção básica não é mais a família, mas a empresa, e depois não é mais a empresa familiar, mas a empresa burocrática, quando os métodos de trabalho tradicionais cedem lugar aos racionais, quando a produtividade e a eficiência se transformam em objetivos básicos das unidades de produção, quando o desenvolvimento econômico se torna o objetivo das sociedades, quando o revestimento se torna uma condição de sobrevivência para as empresas, quando, enfim, o padrão de vida começa a aumentar de forma automática, autônoma e necessária. (BRESSER-PEREIRA, 2003, p. 33 -34)

Além disso, foi um momento histórico em que alguns países do mundo, assim como na Europa, passaram por um momento chamado de Revolução de 30 (Lamounier, 1992), com 
contrastes da revolução política e luta de classes, ou seja, as massas populares atravessadas pela oposição entre a pessoa e a coisa.

Para Pêcheux (1977) falar das massas populares, de mudanças políticas e de revolução, enfim, da história, em termos de pessoas e de coisas, de sujeitos e objetos, de intenções e de estado das coisas, como algo natural, como distinções transparentes que aparecem na linguagem sem qualquer ambiguidade, é desconsiderar totalmente a constituição essencialmente ideológica do discurso e do sentido; o que se pode perceber no pronunciamento de Vargas da ambiguidade e a produção de sentidos que este sujeito-político quer interpelar.

\section{O DISCURSO ENUNCIADOR DE VARGAS NO PRONUNCIAMENTO DE POSSE DO ANO DE 1951}

Os dicionários de Dominique Maingueneau e Patrick Charaudeau Dictionnaire d'analyse du discours, publicado pela Éditions du Seiul, Paris, 2002 e o organizado por Detrie, C; Siblot, P.; Verine, B.Termes et conceptspour l'analyse du discours: une approche praxématique Honoré Champion, Paris, 2001 (apud BARONAS, P. 06) traz aqui para tentar identificar o enunciador o posicionamento "ao analisar gêneros e evidenciar que nesses gêneros é possível constatar, além dos "locutores empíricos, os indivíduos que compõem o grupo e, do ator coletivo do qual esses locutores empíricos participam: um partido, um conjunto de manifestantes, uma associação" a existência de um terceiro nível de enunciação o qual denomina de hiperenunciador. Trata-se de uma instância enunciativa que "funda os diversos pontos de vista expressos por esse ator: "a Esquerda", "a Nação", "o Clube" etc". Desse modo, "enquanto [o ator coletivo] tem por referentes grupos de locutores que formam uma organização em um momento e lugar determinados, [o hiperenunciador] tem por referentes entidades de alguma forma transcendentes" que em última instância é quem validam as enunciações. "

Assim, o hiperenunciador desliza para a paráfrase que consta a subjetividade, ou seja, o centro de toda a enunciação que desloca do eu e passa a ser visto como inerente a toda a linguagem, o qual se pode perceber no recorte na fala pessoal do sujeito enunciador que consta no final do pronunciamento de posse do ano de 1951 onde se escreveu "quero exprimir a minha inteira confiança no aprimoramento dos nossos costumes políticos, no progresso $e$ aperfeiçoamento das práticas democráticas e na participação cada vez mais numerosa $e$ substancial do povo nos problemas e nas decisões da vida nacional".

Todavia, podemos pensar que mediante esta análise dos pronunciamentos em busca da tentativa da resposta do nosso objetivo da pesquisa sobre se o político pode influenciar as massas, percebemos a estruturação de um ponto que desliza nos pronunciamentos que é chamado por Pêcheux (1979) de a "língua de vento" que sustenta a política do performativo, a questão de saber quem está 'no direito de produzir os enunciados performativos, que a propósito da revolução (palavra esta citada pelo sujeito-governante Vargas nos seus dois pronunciamentos de posse) sendo uma nova resposta, ambígua e flutuante, remetendo ao mesmo tempo à "cada um" e a "ninguém" daqueles que denominam-se massas, pois na política do performativo é desenvolvido as atividades do imaginário, ou seja "o dizer" neste contexto político "equivale a fazer", e o fazer pertence ao imaginário daquele que o diz imaginando controlar as massas. 


\section{SERIA O “NÃO DITO" UMA POSSÍVEl alternatiVA tOMADA POR GETÚlIO VARGAS}

O não dito produz mais sentidos na análise de discurso, ao colocar a relação com o dito, se pode construir um dispositivo de interpretação no qual o sujeito expressa o que não quer dizer para que produza efeitos na interpretação das massas.

O que nos chama a atenção é que antes da criação daquilo que não existia é colocado o cenário amplo, o qual o pronunciamento propõe que "em toda a nossa história", ou seja, história de quem?

Orlandi (2009) diz que somos afetados pela língua e pela história, seu gesto de interpretação produzia todos esses efeitos, assim Vargas no seu gesto de dizeres em um discurso cujo o corpus foi relacionado a um momento de transição revolucionária, propõe a chamada de interesses para aquilo que estava para construir materializando o dizer.

O sujeito produz o enunciado e seus dizeres nem sempre são, conforme Orlandi (2009, P.28), neste caso, o analista precisa estar atento aos 'dizeres que não são', como é descrito a seguir:

Os dizeres não são, como dissemos, apenas mensagens a serem decodificadas. São efeitos de sentidos que são produzidos em condições determinadas e que estão de alguma forma presentes no modo como se diz, deixando vestígios que o analista de discurso tem que aprender. São pistas que ele aprende a seguir para compreender os sentidos aí produzidos. Pondo em relação ao dizer com sua exterioridade, suas condições de produção. Esses sentidos têm a ver com o que é dito ali, mas também em outros lugares, assim como com o que não é dito, e com o que poderia ser dito e não foi. Desse modo, as margens do dizer, do texto, também fazem parte dele.

Também, quando Vargas em seu pronunciamento coloca "a vontade do povo brasileiro, afinal senhor de seus destinos e supremo árbitro de suas finalidades coletivas". Neste caso, analisemos a paráfrase 'vontade do povo brasileiro', levando em consideração o efeito de sentido que produz no discurso, ao afirmar a vontade de uma nação, Vargas generaliza, e ao mesmo legitima que o desejo de todas as pessoas que estavam naquele momento histórico dentro de um território, numa condição de produção específica, tem a mesma vontade.

O que se pode pensar ao falar de controle das massas é que o sujeito-orador argumenta e molda seu público para uma aprovação de sua vontade.

\section{O DISCURSO DE VARGAS NA TENTATIVA DE ATENDER OU MOVER (OU ACREDITAR SER POSSÍVEL) OS ANSEIOS DAS MASSAS POPULARES}

No livro de D'Araújo (1992), a autora faz uma menção à história de Vargas no período de 1950, que antecede e precede a posse do Presidente nesta época, como segue: 
(...) versões mais correntes costumam dividir o período constitucional de Vargas em dois momentos distintos.

O primeiro iria de 1951 até meados de 1953, e seria marcado por uma política de conciliação com os setores conservadores, evidenciada na composição do seu primeiro ministério: o "Ministério da Experiência". Sob essa ótica de conciliação de interesses, a política econômica governamental pautava-se por uma conduta de composição com os setores mercantis da burguesia e do capital estrangeiro, em detrimento de uma linha de atuação mais ofensiva em relação aos interesses da indústria, do nacionalismo e do trabalhismo. Grosso modo, esse primeiro momento do Governo estaria configurado por conflitos internos aos setores dominantes, pela aliança com os setores médios e por um acomodamento das massas frente ao Governo. (D'ARAUJO, 1992 p.21)

Como explicitado pela autora supracitada, este primeiro momento do governo no período de 1951, trata-se de um governo de novidades mercadológicas e divisão de intensões políticas partidárias, as palavras indústria, nacionalismo e trabalhismo tornou-se um enunciado do Governo de Vargas neste período, o contexto de seu pronunciamento de posse revela os propósitos que o governante ora populista inseria mediante sua linguagem, pela língua e história de uma memória de contradições.

Outro momento da fala de Vargas no pronunciamento foi "com este ato solene encerra-se o prélio eleitoral de que participei e saí reconfortado pelas preferências da maioria da opinião popular", aqui tem o nosso recorte na paráfrase "saí reconfortado pelas preferências da maioria da opinião popular"; o que nos chama a atenção é que neste momento Vargas diz sobre o "reconforto" sentimento este que até então não foi demonstrado no discurso de 1930, já que este governo estava enérgico e determinado às suas pretensões. $E$, o reconforto da maioria da opinião popular, contextualiza o que de fato é importante para Vargas neste período, a intenção da produção de sentidos para a massa é alvo do seu interesse, pois agora ele era populista e democrático, um governo que depende da opinião pública.

Para Molina (1997, P.108), "se pensarmos no discurso populista além da visão tradicional como produtor de um 'efeito de manipulação', podemos cruzar com as vertentes do 'popular' e levantar alguns dados de sua eficácia. Por que deu certo este discurso? Quais referências de sua credibilidade e força, já que desenvolveu a política do país por mais de 30 anos? O que faz dele, ainda hoje, uma imagem mais poderosa, que ainda assombra o presente? "

As interrogações de Molina nos propõem uma conversa com o objetivo de pesquisa deste trabalho, "o que (não) há no discurso do político que move as massas? "

Ao analisar as questões acima como a "noção de manipulação para conduzir a mobilização das "massas", o termo "manipulação" que no dicionário Aurélio propõe no sentido pejorativo "Falsificação da realidade que busca induzir alguém a pensar de determinada forma, manipulação de informações, ou seja, qualquer manobra que visa oculta e suspeitadamente alterar a realidade, falsificando-a", já na análise de discurso descartamos essa possibilidade de "falsificação ou alteração da realidade", pois no tocante do "real" para a psicanálise que traz o conceito para a análise de discurso, trata da linguagem como algo de ordem inconsciente, ligada ao imaginário. Para Moreira e Pinto (2012) a noção da linguagem é manifestada pelo real, no entanto, aqui neste texto para atender a análise de discurso dos pronunciamentos, vejamos as questões levantadas pelos autores: 
De onde vem a palavra? De onde vem a linguagem? A psicanálise nos responde: de das Ding. A figura de Deus condensaria esse algo que escapa radicalmente. Esse ponto poderia ser correlacionado ao real da ilusão, (...) essa dimensão real na ilusão seria o “'real imaginário' (o misterioso je ne sais quoi, o 'algo' insondável que introduz uma divisão autoimposta em um objeto ordinário, permitindo assim que a dimensão do sublime brilhe através dele) "(...) É o que está efetivamente 'para além da imagem'. (MOREIRA; PINTO, p.402)

Nisso o sujeito-Vargas, sujeito-governante, sujeito-político, nas suas incorporações imaginárias, faz também a metáfora do herói neste período, pois o populista ocorreu também com a valorização do trabalho e da instauração das empresas para movimentar a economia e aumentar as vagas de trabalho.

Para Freud o sujeito transfere a imagem metafórica de herói, cria um mito que "é o passo com o qual o indivíduo emerge da psicologia de grupo. O primeiro mito foi certamente o psicológico, o mito do herói; o mito explicativo da natureza deve tê-lo seguido muito depois". Um exemplo deste cenário é que "o poeta que dera esse passo, com isso libertando-se do grupo em sua imaginação, é, não obstante capaz de encontrar seu caminho de volta ao grupo na realidade - porque ele vai e relata ao grupo as façanhas do herói, as quais inventou. Para Freud, "no fundo, esse herói não é outro senão ele próprio. Assim, desce ao nível da realidade e eleva seus ouvintes ao nível da imaginação. Seus ouvintes, porém, entendem o poeta e, em virtude de terem a mesma relação de anseio pelo pai primevo, podem identificar-se com o herói".

Vargas neste período foi visto como populista, no imaginário o que é popular se faz na metáfora de "herói" de alguma forma, no caso deste governante o trabalho desempenhado por ele se torna bem quisto aos olhos da população que de uma certa forma o aprova para mais um mandato.

Aquilo que é chamado de "ato heroico" na memória, está descrito nas palavras de Maria Celina D'Araújo (1992, p. 108):

Quanto à primeira, deve-se ter em mente que a simples denúncia da capacidade espoliativa dos investimentos estrangeiros sobre a economia nacional configurava um posicionamento não-usual para os governantes brasileiros da época. Essa postura tornava-se ainda mais delicada em face do clima de hostilidade gerado pela "guerra fria", que cobria de suspeitas qualquer atitude que trouxesse, implícita ou explícita, uma conotação de independência ou de alheamento frente à nova configuração mundial do poder. Em plena disputa entre os dois blocos - Estados Unidos e URSS".

Neste momento, o Brasil sofria reflexos da Guerra Fria, o impacto da economia global afetava o país que também passava por um conflito político, podemos dizer que muitos contextos de ordem negativo no sentido sócio-político-econômico afetava toda uma população que já estava temerosa dos futuros acontecimentos já registrados na história e na insegurança de um futuro que Ihe gerasse a possibilidade de um equilíbrio que não se sabia até então a quem recorrer, segue então a necessidade de um "herói" que tome outro caminho, talvez diferente e eficaz para salvar toda uma população que já estava em meios a guerras e desespero.

Nisto, D’Araújo (1992, p. 108), entra a decisão do Governante atual que propõe um caminho adverso ao que o mundo externo estava engrenado, vejamos: 
(...) Vargas optava por uma terceira via: a do desenvolvimento autônomo e independente, não-subordinado ou alinhado diretamente a qualquer potência econômica internacional. Considerando que as contingências históricas inviabilizavam essa auto deliberação por parte da maioria das nações, a proposta tornava-se ainda mais vulnerável, tendo em vista que a não subordinação econômica acabaria sendo traduzida como nãoalinhamento político, bastante temido à época. Além disso, a proposta investia-se de um caráter " heroico", já que implicava resistir a pressões externas e a interesses internos organizados e comprometidos com uma maior internacionalização da economia.

No dito de Vargas em seu pronunciamento em 1951 está "Não pretendo evocar os episódios dessa memorável campanha, tão recentes e vivos na memória de todos", a memória que este governante está dizendo é lido como a possibilidade de dizeres que se atualizam no momento da enunciação, do desfecho ocorrido em governos de outrora que estavam sobre seu poder e que foram evidenciados para as massas junto as lutas de poderes, porque senão haveria um esquecimento que corresponde a um processo de deslocamento da memória como a virtualidade de significações.

Ao complemento do recorte do discurso acima disposto Vargas diz "O que desejo proclamar, nesta excepcional oportunidade, é a vitória dos ideais pelos quais sempre porfiei e foram o sonho acariciado de muitas gerações: a vitória da liberdade, da garantia e da legitimidade do voto popular", neste o governado se refere à criação de uma contextualidade que produzirá sentidos outros para as massas, e com isso o apoio maciço dos indivíduos, ou seja, neste está a relação da linguística com as formações sociais, o dito sobre o não dito que contribui para uma aparente produção de equívocos e unívoca sobre a realidade brasileira da época.

\section{CONCLUSÃO}

Este trabalho levou em consideração questões criam a possibilidade de um norte para análise, e, buscar entender as formações imaginárias para tomar o objeto ( $R$ - referente) do sujeito presidente (A) em relação aos sujeitos cidadãos (B).

As marcas nas superfícies linguísticas dos textos dos discursos podem apontar para o modo como as relações de poder/ de força estão ali produzindo sentidos, e, ainda discutir a noção de 'massas' conforme Pêcheux (2014), em relação às noções de 'influência'/"convencimento' e 'mudança de comportamento', tomando como base para essa reflexão o aforismo que diz que não se pode pensar do lugar do outro, e o de que somos sujeitos divididos pelo inconsciente e interpelados pela ideologia, duas premissas que implicam a singularidade e subjetividade muito fortemente.

Com estes objetivos trouxemos algumas questões descritas nos temas sobre Getúlio Vargas em seus dois momentos do seu mandato na história da nação que dirigiu, o que propõe a tentativa de compreender o funcionamento dos opostos de tais momentos e tais posições.

Assim, fazer pensar nas questões que abrangem e possível influência das massas, como: de que massas o político precisa? O que o sujeito pensa que são as massas? É possível 
influenciar/convencer o outro interlocutor? Em que medida os efeitos de sentido se tornam únicos e mais verdadeiros/apropriados que outros?

Buscamos também sustentação na teoria da argumentação/retórica argumentativa. Então, ao tentar responder estas questões, ou criar uma possibilidade de entendimento no decorrer das considerações nos temas e numa análise do discurso de posse, pode-se compreender que não podemos falar pelo outro, e também não há garantia de influência ou de convencimento, pois todos são atravessados pela ideologia e suas condições de produção são individuais.

Enfim, baseamos muito de nossa tentativa de entendimento e no embasamento das teorias de autores citados neste artigo, e buscamos compreender que enquanto sujeitos inseridos em determinadas formações sociais, estamos em interlocução constante e que, para isso, nos filiamos de forma inconsciente a nichos de sentidos, às formações discursivas. Ao mesmo tempo, somos interpelados pela ideologia a dar sentidos ao que nos rodeia. Esse processo ideológico de interpelação é um mecanismo de interpretação que produz e reproduz a realidade como da ordem da evidência.

\section{REFERÊNCIAS}

AURÉLIO, Dicionário da língua portuguesa. 4a edição revista e ampliada do dicionário Aurélio. 7ạ impressão. Rio de janeiro, 2002.

BARONAS, Roberto Leiser. Efeito de sentido de pertencimento à análise de discurso. (Disponível em:

$<$ http://www.ufrgs.br/analisedodiscurso/anaisdosead/2SEAD/SIMPOSIOS/RobertoLeiserBaronas.p df $>$ (Acesso em 25.01.2019)

BRESSER-PEREIRA, Luiz Carlos. Desenvolvimento e crise no Brasil: história, economia e política de Getúlio Vargas a Lula. São Paulo: Edição34, 2003. (Disponível em: $<$ https://books.google.com.br/books?hl=pt-

PT\&Ir=lang_pt\&id=EMMvv_sV9bUC\&oi=fnd\&pg=PA25\&dq=getulio+vargas\&ots=euTFIzkhur\&sig=Q KKkv-WpiYhJMEvdffCrQwiBAJU\#v=onepage $\& q=$ getulio\%20vargas $\& f=f a l s e>\quad$ ACESSO $\quad$ EM 19/04/2019.

COTRIM, Lívia Cristina de Aguiar. O ideário de Getúlio Vargas no Estado Novo. Universidade Estadual de Campinas. Campinas, SP. 1999.

D'ARAUJO, Maria Celina. O segundo governo Vargas 1951-1954: democracia, partidos e crise política. 2. ed. São Paulo: Ática, 1992. 206 P. (Série Fundamentos ; 90).

DISCURSO pronunciado, por ocasião da posse como Chefe de Governo Provisório da República - 03 de novembro de 1930 - (Vide Biblioteca da Presidência da República - Acesso: http://www.biblioteca.presidencia.gov.br/presidencia/ex-presidentes/getulio-

vargas/discursos/1930/03.pdf/view

DISCURSO de posse - 1951 - No Tribunal Superior Eleitoral (Vide Biblioteca da Presidência da República - Acesso: http://www.biblioteca.presidencia.gov.br/presidencia/ex-presidentes/getuliovargas/discursos/discursos-de-posse/discurso-de-posse-1951/view

FREUD, S. (1921). Psicologia das massas e análise do ego. In: FREUD, S. Edição standard brasileira das obras psicológicas completas de Sigmund Freud. v. 18. Rio de Janeiro: Imago, 1990. 
LAMOUNIER, Bolívar. 0 modelo institucional dos anos 30 e a presente crise brasileira. Estud. av. [online]. 1992, vol.6, n.14 [cited 2019-08-08], pP.39-57. Available from: <http://www.scielo.br/scielo.php?script=sci_arttext\&pid=S0103-

40141992000100004\&lng=en\&nrm=iso>. ISSN 0103-4014. http://dx.doi.org/10.1590/S010340141992000100004.

MASSMANN, Débora. Retórica e argumentação: percurso de sentidos na biculturalidade. Campinas, SP: Pontes Editores, 2017.

MOLINA, Ana Heloísa. Fenômeno Getúlio Vargas: Estado, Discursos e Propagandas. Hist. Ensino, Londrina, v.3, P.95-112, abro 1997.

MOREIRA, Claudia Maria Silva; PINTO, Jeferson Machado. Para além da ilusão: o real na crítica freudiana à religião. Ágora (Rio de Janeiro) v. XV número especial dez 2012 389-404.

NETO, Lira. Getúlio: Do Governo Provisório à ditadura do Estado Novo (1930-1945). Companhia das Letras, 2013. (Disponível em www.LeLivros.Info).

ORLANDI, Eni de Lourdes Puccinelli. Análise de Discurso: princípios e procedimentos. 5. ed. Campinas / SP: Pontes Editores, 2003.

ORLANDI, Eni Puccinelli. Análise de Discurso: princípios e procedimentos. 8a ed. Campinas: Pontes, 2009.

PÊCHEUX, Michel. (1975) Semântica e Discurso: uma crítica à afirmação do óbvio. 2a edição. Campinas: Editora da Unicamp, 1995.

PÊCHEUX, Michel. [1983] O Discurso: estrutura ou acontecimento. Campinas, SP: 4ạ edição. Pontes Editores, 2006.

PÊCHEUX, Michel. (1977) As Massas Populares são um Objeto Inanimado?. Trad. Suzy Lagazzi. In: Orlandi, E. (org.) Análise de Discurso - Michel Pêcheux. Campinas: Pontes, P.251-273, 2011.

PÊCHEUX, Michel. (1979) Foi “propaganda” mesmo que você disse?. In: Orlandi, E. (org.) Análise de Discurso - Michel Pêcheux. Campinas: Pontes, P.73-92, 2011

PÊCHEUX, Michel. Análise de Discurso. Textos selecionados por Eni Puccinelli Orlandi. Campinas, SP: 4ạ edição. Pontes Editores, 2014.

PFEIFFER, Cláudia Castellanos. Bem dizer e retórica: um lugar para o sujeito. Campinas, SP:2000. 